\title{
A cluster-based randomized controlled trial promoting community participation in arsenic mitigation efforts in Bangladesh
}

Christine Marie George ${ }^{1 *}$, Alexander van Geen², Vesna Slavkovich', Ashit Singha ${ }^{3}$, Diane Levy ${ }^{4}$, Tariqul Islam ${ }^{5}$, Kazi Matin Ahmed ${ }^{6}$, Joyce Moon-Howard ${ }^{7}$, Alessandro Tarozzi ${ }^{8}$, Xinhua Liu ${ }^{4}$, Pam Factor-Litvak ${ }^{9}$ and Joseph Graziano'

\begin{abstract}
Objective: To reduce arsenic (As) exposure, we evaluated the effectiveness of training community members to perform water arsenic (WAs) testing and provide As education compared to sending representatives from outside communities to conduct these tasks.

Methods: We conducted a cluster based randomized controlled trial of 20 villages in Singair, Bangladesh. Fifty eligible respondents were randomly selected in each village. In 10 villages, a community member provided As education and WAs testing. In a second set of 10 villages an outside representative performed these tasks.
\end{abstract}

Results: Overall, $53 \%$ of respondents using As contaminated wells, relative to the Bangladesh As standard of $50 \mu \mathrm{g} /$ $L$, at baseline switched after receiving the intervention. Further, when there was less than $60 \%$ arsenic contaminated wells in a village, the classification used by the Bangladeshi and UNICEF, 74\% of study households in the community tester villages, and $72 \%$ of households in the outside tester villages reported switching to an As safe drinking water source. Switching was more common in the outside-tester (63\%) versus community-tester villages (44\%). However, after adjusting for the availability of arsenic safe drinking water sources, well switching did not differ significantly by type of As tester (Odds ratio $=0.86$ [95\% confidence interval 0.42-1.77). At follow-up, among those using As contaminated wells who switched to safe wells, average urinary As concentrations significantly decreased.

Conclusion: The overall intervention was effective in reducing As exposure provided there were As-safe drinking water sources available. However, there was not a significant difference observed in the ability of the community and outside testers to encourage study households to use As-safe water sources. The findings of this study suggest that As education and WAs testing programs provided by As testers, irrespective of their residence, could be used as an effective, low cost approach to reduce As exposure in many As-affected areas of Bangladesh.

Keywords: Arsenic, Health educational intervention, Bangladesh

\footnotetext{
* Correspondence: cmg2140@columbia.edu

'Department of International Health, Program in Global Disease Epidemiology and Control, Johns Hopkins Bloomberg School of Public, 615 N. Wolfe Street, Room E5535, Baltimore, Maryland 21205-2103 Full list of author information is available at the end of the article
} 


\section{Introduction}

Exposure to elevated levels of inorganic arsenic (As) is associated with cancers of the skin, bladder, and lung [13], developmental effects [4,5], cardiovascular disease $[6,7]$, and skin lesions $[8,9]$. Chronic As exposure is also associated with deficits in childhood cognitive and motor function $[5,10,11]$. Recent data suggest associations between chronic As exposure from drinking water and mortality [12].

Groundwater pumped from approximately half the estimated 10 million tubewells in Bangladesh do not meet the World Health Organization (WHO) guideline for As of $10 \mu \mathrm{g} / \mathrm{L}$ [13]. In 2006, Ahmed et al reported that $57 \%$ of the estimated population of $28-35$ million initially exposed to As above the Bangladesh standard of $50 \mu \mathrm{g} / \mathrm{L}$ remain exposed. The most commonly used As mitigation option is well switching (67\%), followed by the use of deep tubewells (28\%) [13]. Mitigation options such as piped water systems, rainwater collection, dugwells, As filters, and pond sand filters are utilized by a very small proportion of the population $[13,14]$.

Even when provided with As education, households do not always seek As-safe drinking water sources [15-18]. Testing programs typically involve a representative from an outside organization coming into a village to test the well water for As. These staff label the spout of each well red if the As concentration is greater than $50 \mu \mathrm{g} / \mathrm{L}$ (Ascontaminated well) and green if the As concentration in the well is less than $50 \mu \mathrm{g} / \mathrm{L}$ (As-safe well). After the results of the As test are provided, the representative typically leaves the village without providing the resources or in-depth knowledge to address health concerns or mitigation options [15]. The lack of resources at the local level, we hypothesize, may be an important factor limiting the impact of As testing programs. Previous interventions have found that the provision of As education and water arsenic (WAs) testing can encourage households with As contaminated wells to switch to alternative drinking water sources [14,19-21]. However, no studies to date evaluated the effectiveness of having a community member, rather than an outside representative, provide these services.

In 2010, we developed an As education and WAs testing intervention for rural villages in Singair, Bangladesh. Our study objective was to evaluate the effectiveness of having community members, compared to outside representatives, conduct WAs testing and As education. The primary study outcome was switching to an As safe well among those with As contaminated wells at baseline; the secondary outcome was the change in urinary As (UAs) concentration. We hypothesized that the community tester would be more effective since they could provide additional reinforcement by living in the village. Community involvement in As testing may provide a sustainable and less costly option for communities to monitor their As exposure and may represent a model for government or non-governmental agencies to conduct future interventions.

\section{Methods \\ Setting}

This study was conducted in rural villages in Singair Upazila, located in the Manikganj district of Bangladesh. This study area was selected due to its wide range of WAs concentrations, and the presence of the Christian Commission for Development Bangladesh (CCDB), a non-governmental organization that assisted with the implementation of this intervention.

\section{Design}

\section{Eligibility and Enrollment}

We first administered a household drinking water survey to the person responsible for primary drinking water collection in 6746 households in 26 villages [22]. Information was collected about: As status of the household's primary drinking water source (safe, contaminated, untested), well depth, and well installation date.

Of the 26 villages, 20 met our criteria of having at least $40 \%$ of wells exceeding the Bangladesh As standard $(50 \mu \mathrm{g} / \mathrm{L})$, and at least 50 individuals who met the study eligibility criteria (Figure 1). Participants had to: 1 ) be the person in the household responsible for primary drinking water collection; 2) be using an untested well; and 3) be 18 years of age or older. Villagers were excluded if: 1) they had an As filter; 2) obtained water from an As treatment plant; or 3) did not have a primary well they used to collect the majority of their household's drinking water (The respondent could be using any well. They did not have to be using a well that they owned.) After confirming the identity and eligibility of participants the interviewer explained the details of the study and obtained informed consent.

This study was a cluster based, randomized controlled trial of 1000 households. Randomization was performed at the village level; participants were clustered within each village. Fifty eligible households were randomly selected based on the household drinking water survey. Each respondent was interviewed at baseline and at follow-up 7-9 months later (Figure 1). In ten villages, a trained community member conducted well WAs testing and provided As education. In the remaining 10 villages, an outside representative, defined as someone living in a different union, performed these tasks. The two groups of villages were geographically separated. Using census data from the Bangladesh Bureau of Statistics, villages were matched on literacy rate and land ownership as these are strong indicators of socioeconomic status [23]. We also attempted to match villages on the proportion of As contaminated wells based on our household drinking water survey. Villages were randomly assigned by the study coordinator to each intervention group at 


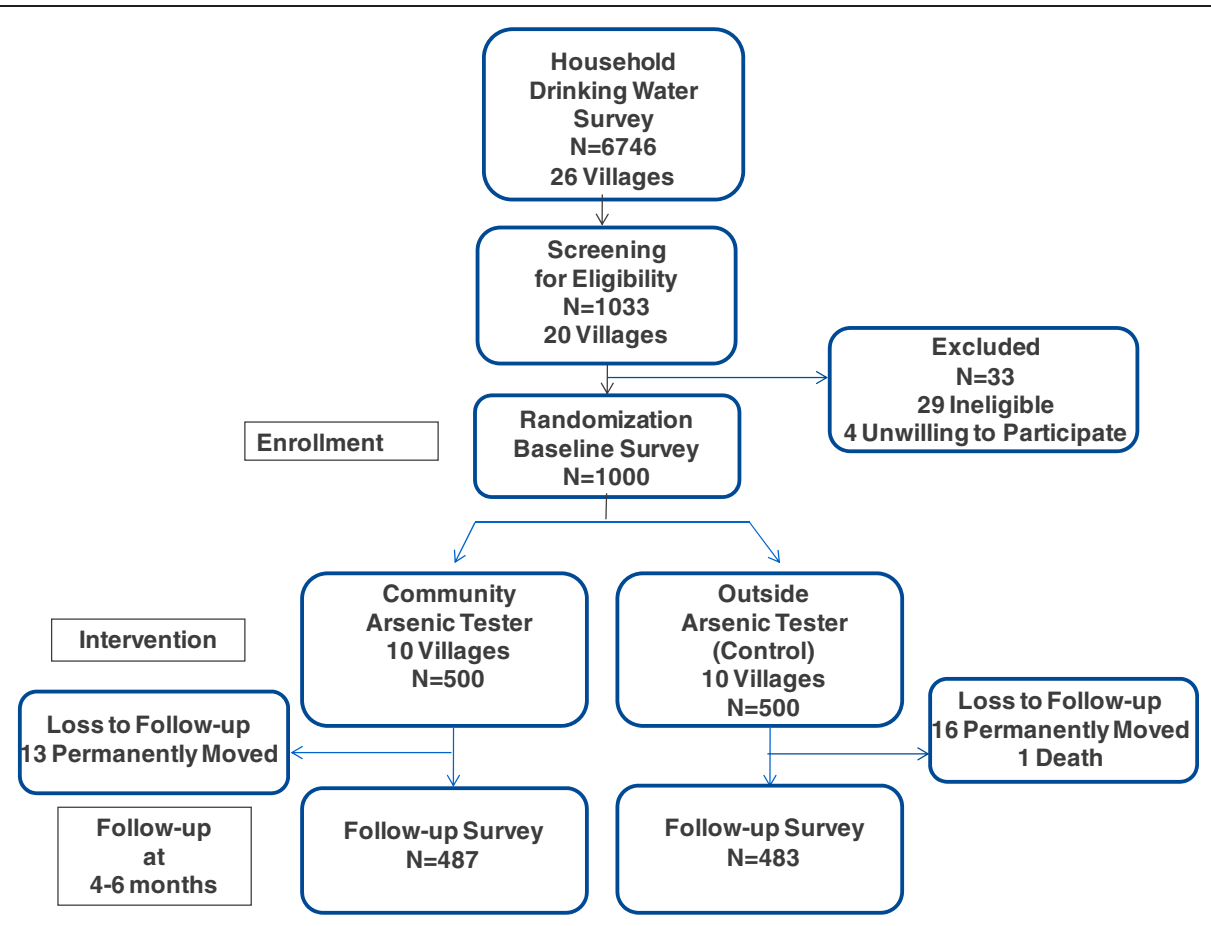

Figure 1 Cluster based randomized controlled trial study design.

baseline using the random number generator in SAS, version 9.2 (SAS Institute Inc., Cary, NC, USA). Study households in each village were randomly selected in the same manner.

\section{Intervention}

The 10 "community-testers" were forum workers for CCDB who organize community activities on health and poverty alleviation. All As testers were required to be at least 18 years of age and literate. The distribution of age, educational level, gender, and religion did not differ significantly between the community and outside testers.

All testers received a one week intensive training on how to measure the As content of wells and effectively disseminate As education. The tester went to each study household at least once to: 1) measure the As concentration of the household's primary drinking water source using an As field testing kit; 2) conduct a structured 40 minute As education session; and 3) provide assistance to participants with As contaminated wells to locate a nearby As-safe drinking water source. These tasks were performed in each study village over a period of 3 months.

The As education materials were developed based on ther current scientific literature regarding the health implications of As exposure, studies assessing the knowledge of As in the population [16,17,24,25], and our As education pilot study. Education sessions focused on key messages regarding the health implications of chronic
As exposure, and methods to reduce exposure. The sessions were designed to be interactive by asking participants questions about the topics being covered. If a participant's primary drinking water source was found to be As contaminated, assistance to locate a nearby Assafe drinking water source was provided. In such cases, participants were asked from which water source they would like to collect their drinking and cooking water. If this water source was found to be As-safe and the well owner agreed, the As tester encouraged the participant to collect all of their drinking and cooking water from this source.

\section{Data Collection}

During the baseline and follow-up surveying periods, interviewers visited each study household to: 1) administer a questionnaire to the person responsible for primary drinking water collection; 2) collect a sample of the primary drinking water source; and 3) collect a urine sample from the study respondent.

Both questionnaires obtained information on water usage, socio-demographics characteristics, and knowledge of As. The participant's knowledge of As was obtained via a 20 item quiz administered at the baseline survey before the start of the intervention and at the follow-up survey. Participants were queried on how to identify As contaminated wells, safe uses of As contaminated water, and the health implications of chronic As exposure. One point was given for a correct item, and zero points for an 
incorrect item. Possible quiz scores ranged between zero and 20.

\section{Arsenic Measurements}

Urinary As concentrations collected at baseline and follow-up were used as a biological index of As exposure. Previous studies have found strong correlations between urinary As and drinking WAs concentrations [20,26,27]. Switching from an As-contaminated to a safe well can reduce urinary Asconcentrations to a level that approaches those of individuals who have been consistently relying on safe wells [20]. Urine samples were collected from study respondents in $50 \mathrm{ml}$ acid washed tubes during the baseline and follow-up periods. Urine samples were placed in portable coolers, then frozen at $-20{ }^{\circ} \mathrm{C}$ at the local laboratory in Dhaka, Bangladesh, and shipped on dry ice to Columbia University. Total urinary As was measured using a Perkin-Elmer AAnalyst 600 graphite furnace system, and adjusted for urinary creatinine $(\mathrm{Cr})$ concentrations according to published methods [28]. Our laboratory is part of a quality control program for total urinary As which is coordinated by the Institut de Santé Publique du Québec (Québec, Canada). During the course of this study, the intraclass correlation coefficient between our laboratory's values and samples calibrated at the Quebec laboratory was 0.99 . The average intra-precision and inter-precision for three control urine samples run daily for this period were $2.6 \%$, and $5.7 \%$, respectively.

WAs field testing was conducted using the Hach EZ As Test Kit (Part No. 2822800) which measures As concentrations in water using a colorimetric scale that ranges from $0-500 \mu \mathrm{g} / \mathrm{L}$. A 40 minute reaction period was used in these studies rather than the manufacturer recommended 20 minutes because a previous study showed that the increased reaction period reduced inconsistencies in the 50-100 $\mu \mathrm{g} / \mathrm{L}$ range [22,29].

WAs measurements conducted using the Hach EZ As test Kit were verified by laboratory analysis at the Geochemistry Research Laboratory at the Lamont Doherty Earth Observatory (LDEO) at Columbia University. The As concentrations were measured using InductivelyCoupled Plasma-Mass Spectrometry (ICP-MS) with a detection limit of $0.1 \mu \mathrm{g} / \mathrm{L}[30,31]$.

\section{Statistical Methods}

The primary hypothesis of this study was that training a community member to perform As testing and provide As education is more effective than sending a trained person from outside the village to conduct these same tasks, conditional on equal competence and similar observed characteristics of the tester.

Based on a previous study conducted in Araihazar, Bangladesh, we assumed that the proportion of well switching would be 0.33 in our outside tester villages and 0.66 in our community-tester villages $[14,21]$. Furthermore, based on the results of our household drinking water survey we estimated that approximately $50 \%$ (500) of the 1000 respondents included into our study population would be using wells that were As contaminated. We specified the type 1 error, the probability of rejecting $\mathrm{H}_{\mathrm{o}}$ when it is true, at $5 \%$ and the type 2 error, the probability of not rejecting $\mathrm{H}_{\mathrm{o}}$ when it is false, at $20 \%$. Thus, we required 18 villages with 35 households each. To account for at least a $10 \%$ loss to follow up, we selected a sample size of 20 villages of 50 households each.

The outcome variables in this study were: 1) questionnaire reported well switching; and 2) change in urinary As concentration. We evaluated the determinants of well switching for study respondents with As-contaminated wells at baseline. Safe and As-contaminated were defined according to the Bangladesh WAs standard of $50 \mu \mathrm{g} / \mathrm{L}$. Chi-square tests and two sample t-tests were used to compare differences between the communitytester and outside-tester villages for categorical and continuous variables, respectively.

Logistic regression was used to estimate the odds of well switching controlling for both individual and village level covariates. Generalized estimating equations (GEE) were used to account for clustering within villages [32]. We estimated the most parsimonious model by eliminating all non statistically significant variables $(\mathrm{p}>0.05)$, except for those a priori specified (ie. Type of As Tester) until the lowest quasi likelihood information criterion (QIC) was determined [32]. All analyses were performed using SAS, version 9.2 (SAS Institute Inc., Cary, NC, USA).

\section{Ethics Section}

The study protocol was approved by the Columbia University Medical Center Institutional Review Board and the Bangladesh Medical Research Council. Informed consent was obtained from all study respondents.

\section{Results}

During our baseline survey, 1033 respondents with untested wells, selected from our household drinking water survey, were screened for eligibility. Of these, 4 ( $0.4 \%)$ were unwilling to participate and $29(2.8 \%)$ were ineligible. At follow-up, 30 (3\%) respondents had either permanently moved [29] or died [1]. Urine was collected from 953 (95\%) respondents at baseline and 930 (96\%) respondents at follow-up. Five hundred and forty three (56\%) respondents were found to be using As contaminated wells, and 427 (44\%) were found to be using As safe wells.

The distribution of age, literacy, religion, baseline quiz score, and land ownership did not differ significantly 
between the two intervention groups. However, the community tester intervention group had more well owners, more As contaminated wells, and lived further away from an As-safe well; they also had significantly higher urinary As concentrations at baseline (Table 1). The number of times the participant met with the As tester was significantly higher for the community-tester versus outside-tester villages; $48 \%$ of participants in the community-tester villages met with the As tester four or more times, compared to 13\% in the outside-tester villages.

Overall, $53 \%$ of respondents with As contaminated wells at baseline switched during the intervention period. Switching was more common in the outside-tester (63\%) versus community-tester villages (44\%). However, after adjusting for the availability of As safe drinking water sources, the association between the As tester and well switching was not significant $(\mathrm{OR}=0.86[95 \%$ CI $0.42-1.77$ )
(Table 3). Follow-up knowledge of As quiz scores were positively related to well switching, although the association did not reach statistical significance (Table 4). The number of times the participants met with an As tester was positively associated with well switching, when the As tester met with the study respondent at least 4 times $(\mathrm{OR}=1.61 ; 95 \%(1.11-2.35))$.

Participants who lived in villages with $\geq 60 \%$ As contaminated wells, classification used by the Bangladeshi and UNICEF, were significantly less likely to switch in comparison to those who lived in villages with $<60 \%$ As-contaminated wells $(\mathrm{OR}=0.25$; 95\% CI (0.13-0.48)). In villages with less than $60 \%$ As-contaminated wells, $74 \%$ of study households in the community tester villages, and $72 \%$ of households in the outside tester villages reported switching to an As safe drinking water source. In contrast to only $35 \%$ wells switching in

Table 1 Baseline and follow-up characteristics by arsenic tester village

\begin{tabular}{|c|c|c|c|}
\hline Characteristics & $\begin{array}{l}\text { Community tester villages } \\
(\mathrm{N}=487)\end{array}$ & $\begin{array}{l}\text { Outside tester villages } \\
(\mathrm{N}=483)\end{array}$ & P-value \\
\hline Age (yrs) [Mean $\pm S D($ Range)] & $36.3 \pm 11.4(18-102)$ & $37.8 \pm 12.8(18-86)$ & 0.07 \\
\hline \multicolumn{4}{|l|}{ Gender (\%) } \\
\hline Female & 99.8 & 100 & 0.32 \\
\hline \multicolumn{4}{|l|}{ Religion (\%) } \\
\hline Muslim & 93 & 95 & 0.14 \\
\hline Hindu & 7 & 5 & \\
\hline \multicolumn{4}{|l|}{ Respondent can read and write (\%) } \\
\hline Yes & 42 & 40 & 0.54 \\
\hline \multicolumn{4}{|l|}{ Head of household education (\%) } \\
\hline No education & 52 & 55 & 0.23 \\
\hline Respondent baseline knowledge of arsenic quiz score mean $\pm S D$ (range) & $8.5 \pm 3.0(0-18)$ & $8.4 \pm 2.9(0-17)$ & 0.77 \\
\hline \multicolumn{4}{|l|}{ Radio ownership (\%) } \\
\hline Yes & 25 & 28 & 0.36 \\
\hline \multicolumn{4}{|l|}{ Land ownership (\%) } \\
\hline No land ownership & 12 & 18 & 0.07 \\
\hline Less than 1 Acre & 63 & 57 & \\
\hline 1 to 2 Acres & 25 & 25 & \\
\hline \multicolumn{4}{|l|}{ Well ownership (\%) } \\
\hline Yes & 82 & 75 & 0.01 \\
\hline \multicolumn{4}{|l|}{ Proportion of unsafe wells in respondent's village(\%) } \\
\hline $0-60 \%$ & 30 & 68 & $<.0001$ \\
\hline \multicolumn{4}{|c|}{ Minutes to an arsenic safe drinking water source for unsafe well owners (\%) $(N=587)$} \\
\hline Less than or equal to 5 minutes & 68 & 32 & $<.0001$ \\
\hline \multicolumn{4}{|l|}{ Arsenic status of tubewell } \\
\hline Safe & 39 & 49 & 0.004 \\
\hline Baseline water arsenic $[\mu \mathrm{g} / \mathrm{L}(\text { Mean } \pm \mathrm{SD}(\text { range }))]^{1}$ & $124 \pm 145(0-500)$ & $117 \pm 147(0-500)$ & 0.66 \\
\hline Baseline creatinine-adjusted urinary As $\left[\mu \mathrm{g} / \mathrm{g} \mathrm{Cr}(\text { Mean } \pm \mathrm{SD}(\text { range) })]^{1}\right.$ & $178 \pm 122.0(9-901)$ & $143 \pm 132(18-1060)$ & 0.0002 \\
\hline
\end{tabular}

*P-values were calculated using a chi-square test for categorical variables and a 2 sample t-test for continuous variables. 1. Water and Urinary Arsenic were log-transformed. 
Table 2 Predictors of well switching among unsafe well users

\begin{tabular}{|c|c|c|c|}
\hline & Total $^{1}$ & $\%$ Who switched ${ }^{2}$ & OR for switching $(95 \% \mathrm{Cl})^{3}$ \\
\hline \multicolumn{4}{|l|}{ Arsenic tester } \\
\hline Outside arsenic tester & 248 & 63 & 1.00 \\
\hline Community arsenic tester & 295 & 44 & $0.86(0.42-1.77)$ \\
\hline \multicolumn{4}{|c|}{ Proportion of unsafe wells in respondent's village } \\
\hline Less than $60 \%$ & 258 & 72 & 1.00 \\
\hline Greater or equal to $60 \%$ & 285 & 35 & $0.25(0.13-0.48)$ \\
\hline \multicolumn{4}{|c|}{ Minutes to safe drinking water source } \\
\hline Less than or equal to 5 minutes & 282 & 63 & 1.00 \\
\hline Greater than 5 minutes & 227 & 43 & $0.55(0.32-0.96)$ \\
\hline \multicolumn{4}{|l|}{ Well ownership } \\
\hline No & 103 & 67 & 1.00 \\
\hline Yes & 440 & 50 & $0.41(0.25-0.65)$ \\
\hline \multicolumn{4}{|l|}{ Radio ownership } \\
\hline No & 398 & 55 & 1.00 \\
\hline Yes & 145 & 47 & $0.64(0.43-0.94)$ \\
\hline
\end{tabular}

(1) "Total" indicates the number of respondents with each attribute. (2) "\% Switching" indicates the percentage of individuals with that attribute that switched wells. (3) OR were adjusted for all variables in the table. Participants with unknown information for any of the covariates were excluded.

villages with greater than $60 \%$ As contaminated wells. In addition, participants who required more than 5 minutes to walk to an As-safe drinking water source were significantly less likely to switch in comparison to those who lived within 5 minutes of an As-safe drinking water source $(\mathrm{OR}=0.55 ; 95 \%$ CI $[0.32-0.96])$. Finally, participants who owned their own well were significantly less likely to switch in comparison to those who did not own their own well $(\mathrm{OR}=0.41 ; 95 \% \mathrm{CI}(0.25-0.65))$.

Among participants with As contaminated wells who changed their drinking water source, the most common

Table 3 Predictors of well switching among unsafe well users

\begin{tabular}{|c|c|c|c|}
\hline & \multicolumn{3}{|c|}{ Total $^{1} \%$ Who switched ${ }^{2}$ OR for switching $(95 \% \mathrm{Cl})^{3}$} \\
\hline \multicolumn{4}{|c|}{ Follow-up knowledge of arsenic quiz score } \\
\hline Q1 (0-11) & 102 & 50 & 1.00 \\
\hline Q2 (12-14) & 146 & 43 & $0.76(0.52-1.12)$ \\
\hline Q3 (15-16) & 103 & 57 & $1.22(0.71-2.10)$ \\
\hline Q4 (17-20) & 192 & 59 & $1.26(0.86-1.85)$ \\
\hline \multicolumn{4}{|c|}{ Number of times met with arsenic tester } \\
\hline 1 Time & 154 & 53 & 1.00 \\
\hline 2 Times & 138 & 52 & $1.24(0.82-1.86)$ \\
\hline 3 Times & 85 & 52 & $1.24(0.80-1.93)$ \\
\hline 4 or more times & 166 & 54 & $1.61(1.11-2.35)$ \\
\hline
\end{tabular}

reported reason for switching was that their baseline well was As-contaminated (92\%). The most common reported reasons for not switching wells were: 1) long distance to a safe well (57\%); 2) family ownership of well (20\%); and 3) owner(s) of safe wells near the respondent's home do not want to share (11\%). Eight percent of respondents with safe wells at baseline switched. The most common reported reason for well switching among these respondents were: 1 ) did not like the taste of their previous well water $(23 \%) ; 2$ ) dug a new well (17\%); and 3) previous well broke (17\%). Similar reasons were given by participants in the two intervention groups.

Overall baseline mean urinary As concentrations were more than double among respondents with As contaminated wells (215 $\mu \mathrm{g}$ As /g Cr) as compared to those using safe wells (91 $\mathrm{g}$ g As /g Cr). At follow-up, the overall mean urinary As concentrations for those with As contaminated wells who switched to safe wells decreased significantly from 194 to $133 \mu \mathrm{g}$ As/g Cr (Figure 2); the reduction did not differ between intervention groups. UAs was essentially the same for those who used As contaminated wells at baseline but did not switch wells ( 245 vs $234 \mu \mathrm{g} \mathrm{As} / \mathrm{g} \mathrm{Cr}$ ). Finally, there was no appreciable change in urinary As concentrations for safe well users. There were a significantly higher number of As tests conducted in the community tester (835) versus outside tester villages(675). This is likely due to the higher number of As contaminated wells in the community testing villages, resulting in the need for additional As testing to locate As safe drinking water sources. 
Table 4 Follow-up characteristics by arsenic tester village

\begin{tabular}{|c|c|c|c|}
\hline Characteristics & $\begin{array}{l}\text { Community tester villages } \\
(\mathrm{N}=487)\end{array}$ & $\begin{array}{l}\text { Outside tester villages } \\
(\mathrm{N}=483)\end{array}$ & $\begin{array}{l}\mathrm{P} \text { - } \\
\text { value }\end{array}$ \\
\hline Respondent follow-up arsenic knowledge quiz score & $14.3 \pm 3.2(4-20)$ & $14.0 \pm 3.6(4-20)$ & 0.2447 \\
\hline \multicolumn{4}{|l|}{ Number of times met with arsenic tester(\%) } \\
\hline 1 Time & 23 & 29 & \multirow[t]{4}{*}{$<0.000$} \\
\hline 2 Times & 18 & 36 & \\
\hline 3 Times & 11 & 22 & \\
\hline 4 or more times & 48 & 13 & \\
\hline \multicolumn{4}{|l|}{ Switching status (\%) } \\
\hline Did Not Switch & 56 & 37 & \multirow[t]{2}{*}{$<.0001$} \\
\hline Switched & 44 & 63 & \\
\hline \multicolumn{4}{|c|}{ Reason for switching, amoung those unsafe well users who switched(\%) $(\mathrm{N}=287)$} \\
\hline Previous tubewell was unsafe for arsenic & 87 & 95 & \multirow[t]{7}{*}{0.121} \\
\hline Previous tubewell broken & 4 & $<1$ & \\
\hline Too many people using previous tubewell & $<1$ & $<1$ & \\
\hline Dug a new tubewell & 4 & $<1$ & \\
\hline Did not like the taste of previous tubewell & 2 & $<1$ & \\
\hline Did not like the color of previous tubewell & 2 & 1 & \\
\hline None of these & $<1$ & 1 & \\
\hline \multicolumn{4}{|c|}{ Reason for not switching, amoung those unsafe well users who did not switched(\%) $(N=256)$} \\
\hline Distance of the safe tubewell was too far & 54 & 58 & \multirow[t]{8}{*}{0.087} \\
\hline Family owns its own tubewell and doesn't wish to impose on others & 15 & 23 & \\
\hline Arsenic safe well had too many users & 5 & 2 & \\
\hline Safe well owner near home does not want to share & 14 & 9 & \\
\hline Physical Limitation & 5 & 2 & \\
\hline Alternative well had bad taste & 3 & 1 & \\
\hline Alternative well had unusual color & 1 & 2 & \\
\hline None of these & 1 & 4 & \\
\hline $\begin{array}{l}\text { Follow-up creatinine-adjusted urinary As }[\mu \mathrm{g} / \mathrm{g} \mathrm{Cr} \text { (Mean } \pm \text { SD } \\
\text { (range))] }\end{array}$ & $163 \pm 157(17-1241)$ & $128 \pm 150(24-1905)$ & $<.0001$ \\
\hline Number of arsenic test conducted & 835 & 675 & 0.0069 \\
\hline
\end{tabular}

\section{Discussion}

Millions in Bangladesh continue to drink groundwater containing elevated levels of As [13]. Many households lack access to As testing services, preventing them from knowing the As status of their wells and locating As-safe water sources in their villages. Thus, there is an urgent need for effective As education and WAs testing programs in Bangladesh [13-15]. This study is the first randomized trial evaluating the effectiveness of community participation in As mitigation in Bangladesh. We hypothesized that community-testers would be more effective than outside-testers in terms of reducing As exposure because the former would offer additional reinforcement by living within the community. Although our data did not support this hypothesis, the intervention program was very successful in encouraging households to use As-safe drinking water sources. Fifty-three percent of participants with As contaminated wells at baseline switched wells at followup, mostly because their baseline well was As contaminated relative to As.

We observed that the reinforcement provided by the availability of an As tester within the village was positively related to well switching. Through their continued presence, the community-tester provided significantly more reinforcement in the village than the outside-tester as evidenced by the number of contacts between the participants and the testers. The knowledge of As quiz scores were significantly higher for respondents at follow-up, compared to baseline, for both intervention groups (Unpublished). 


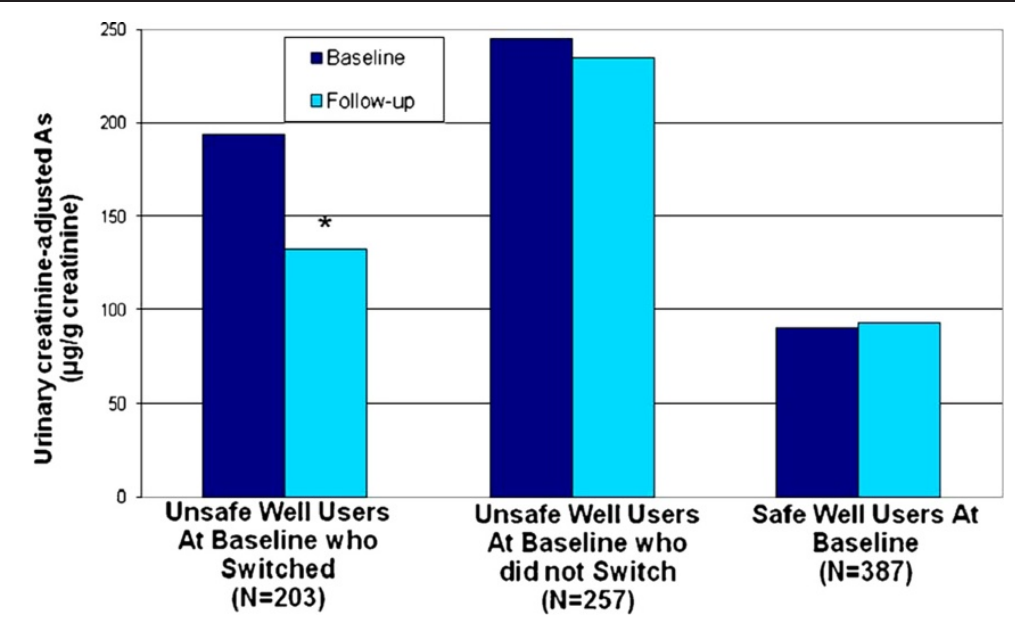

Figure 2 Mean urinary creatinine-adjusted As levels for study respondents ${ }^{*} \mathrm{P}<.0001$ as compared to baseline using a paired $\mathrm{t}$-test where urinary arsenic was log transformed.

We observed significant reductions in UAs concentrations for As-contaminated well users who reported switching wells at follow-up, indicating that our intervention was successful in reducing a biomarker of As exposure. Previous studies in Taiwan indicate that a reduction of As exposure may reduce associated mortality from renal diseases [33,34], intracerebral hemorrhage [35], and ischemic heart disease [36]. A study in Chile found that reduced As intake was associated with decreased numbers of micro-nucleated cells in the bladder [37].

Sources of dietary As such as cooking rice in contaminated water or using rice with elevated As concentration can contribute to elevated urinary As concentrations [38,39]. Therefore it is possible that food As has contributed to the ingested dose of As in our study population. However the literature suggests that when water As concentrations exceed $50 \mu \mathrm{g} / \mathrm{L}$ that ingested water As is the dominant exposure route [39]. In our educational program we encouraged households to both drink and cook with As safe water. Only $8 \%$ of study respondents using As contaminated wells at baseline who switched to safe wells at follow-up reported using their previous tubewell for cooking.

Our findings are consistent with an intervention for 11,746 participants conducted in Araihazar, Bangladesh. That intervention, administered over a two-year period, involved WAs testing and labeling, village level As education, and the targeted installation of deep tubewells with low WAs. At follow-up, 58\% of As contaminated well users and $17 \%$ of safe well users had switched to new drinking water sources. A $46 \%$ reduction in UAs was observed for those with As-contaminated wells who switched to As-safe drinking water sources [20]. Our current intervention was conducted over a much shorter duration and did not involve the installation of deep tubewells, yet we observed roughly comparable results.

The unavailability of As-safe drinking water sources, i.e. the proportion of As-contaminated wells, in a village was the greatest barrier to well switching. In villages with less than $60 \%$ As contaminated wells, $72 \%$ of respondents with As-contaminated wells switched, compared to $35 \%$ well switching in villages with greater or equal to $60 \%$ As-contaminated wells. This is consistent with Hanchett et al., who found that the unavailability of As-safe water sources was a barrier to well switching in six districts of Bangladesh [15]. In our study, the time to walk to As-safe water source was also a significant barrier to well switching. Previous studies have indicated that well switching significantly declines if the nearest safe well is located more than 100 meters away $[14,20,21]$. Well ownership was also a significant barrier to well switching, likely because well owners are more reluctant to shift from a well in which they invested their own money. All of these barriers to well switching were significantly higher in the community versus outside tester villages suggesting a possible reason for the lower well switching observed in these villages.

Our study suggests that WAs testing and As education programs would be most effective in areas where $<60 \%$ of wells are As-contaminated. In these villages the vast majority of respondents with contaminated wells switched (72\%). A recent report of a nationwide survey in Bangladesh indicated that $77 \%$ of the population lives in areas with between 0-60\% of their wells being As contamination [40]. Therefore our intervention is a viable option for the majority of the population residing in As 
affected areas of Bangladesh. For the $23 \%$ of the population who reside in areas with $>60 \%$ As-contaminated wells, this intervention will likely need to be combined with the provision of alternative mitigation options such as the installation of deep tubewells, As filters, or rain water harvesting.

A major limitation of our study was the relatively short three month duration of our intervention period. We hypothesized that community-testers would be more effective than outside-testers because of their additional reinforcement. While we did observe that the communitytesters provided significantly more reinforcement than the outside testers, this did not appear to increase their effectiveness in reducing As exposure. We attribute this result in part to the significantly higher proportion of As-contaminated well located in the community-tester villages and in part to the short duration of the study. Nevertheless, the use of the community-testers provides a potentially sustainable approach for As mitigation because of the continued presence of the testers in villages over time to provide additional reinforcement and WAs testing services. Further, community testers will likely be less costly because they do not require transportation costs. We recommend that if this intervention approach is upscaled that it be incorporated in existing community health worker programs conducted by non-governmental organizations or by local government. This would reduce the required operation cost. Working with existing organizations would also allow for greater accountability of those providing the As testing and education and make refresher trainings over time easier to organize.

\section{Conclusions}

In conclusion, the overall intervention was effective in reducing As exposure provided there were As-safe drinking water sources available. However, there was not a significant difference observed in the ability of the community and outside testers to encourage study households to use As-safe water sources. The findings of this study suggest that As education and WAs testing programs provided by As testers, irrespective of their residence, could be used as an effective, low cost, easy to deliver intervention approach to reduce As exposure in many As-affected areas of Bangladesh. Furthermore, this approach has the advantage of not involving costly As filters, deep tubewells, or As treatment plants.

\section{Competing Interests}

The authors have no competing interests.

\section{Authors' contributions}

This study was a multidisciplinary international collaboration that required significant expertise of scientists with diverse public health, earth sciences, and social science. For this reason there are twelve authors on the paper. $\mathrm{C}$ M G directed the field study, performed the statistical analysis, and wrote the first draft of the manuscript. J G and A V G directed the studies and revised the manuscript. Pam Factor-Litvak assisted with the analysis of the data presented in the manuscript and provided substantial comments to several drafts. All individuals named on the article provided comments to several drafts of the article and approved the final version.

\section{Acknowledgements}

This study was supported by funds from the National Institute of Health grant number NIEHS ES P42 10349 and the Earth Institute at Columbia University. In addition, Christine Marie George was the recipient of an EPA Star Fellowship and a Fulbright Fellowship. We would like to thank the Christian Commission for Development Bangladesh (CCDB) and our arsenic testers for their support of our project: Dr. Afroz Mahal and Almas Hossain. We would also like to thank the staff at the Columbia University Arsenic \& Health Research in Bangladesh office and our interviewers from Dhaka University, Department of Geology for their tireless support: Khaled Hasan, Zakir Hossain, Sawkat Haiat Sarwar, Dr. Rakibuz Zaman, Dr. Mahfuzar Rahman, Dr Abu Bakar Siddique, Golam Sarwar, Nur-E-Azam Sarwar, Shariful Islam Khan, Lisma Akhter, Shawkat Jahangir, Shahid Ahmed Sorwar, Nahid Farjana, Tahmina Akter, Jesmin Neher, Murad Hossain, Ershad Bin Ahmed, Iftakharul Alam, Jahid Alam, Masud Al Noor, Majibul Hosain, Anisur Rahaman Khan, Jismin Neher, Jakir Hossain Mir, Kalpana Rani Das, and Abul Kalam Azad.

\section{Author details}

${ }^{1}$ Department of International Health, Program in Global Disease Epidemiology and Control, Johns Hopkins Bloomberg School of Public, 615 N. Wolfe Street, Room E5535, Baltimore, Maryland 21205-2103. 2Lamont-Doherty Earth Observatory of Columbia University, Palisades, New York, USA. ${ }^{3}$ Christian Commission for Development Bangladesh (CCDB), Dhaka, Bangladesh. ${ }^{4}$ Department of Biostatistics, Mailman School of Public Health, Columbia University, New York, NY, USA. ${ }^{5}$ Columbia University Arsenic \& Health Research in Bangladesh, Dhaka, Bangladesh. ${ }^{6}$ Department of Geology, Dhaka University, Dhaka, Bangladesh. ${ }^{7}$ Department of Sociomedical Sciences, Mailman School of Public Health, Columbia University, New York, NY, USA. ${ }^{8}$ Department of Economics, Duke University, Durham, NC, USA. 'Department of Epidemiology, Mailman School of Public Health, Columbia University, New York, NY, USA.

Received: 10 December 2011 Accepted: 31 May 2012

Published: 19 June 2012

\section{References}

1. Marshall G, Ferreccio C, Yuan Y, Bates MN, Steinmaus C, Selvin S, et al: Fiftyyear study of lung and bladder cancer mortality in Chile related to arsenic in drinking water. J Natl Cancer Inst 2007, 99(12):920-8.

2. Chen $\mathrm{Y}$, Ahsan $\mathrm{H}$ : Cancer burden from arsenic in drinking water in Bangladesh. Am J Public Health 2004, 94(5):741-4.

3. Morales KH, Ryan L, Kuo TL, Wu MM, Chen CJ: Risk of internal cancers from arsenic in drinking water. Environ Health Perspect 2000, 108(7):655-61.

4. Calderon J, Navarro ME, Jimenez-Capdeville ME, Santos-Diaz MA, Golden A, Rodriguez-Leyva I, et al: Exposure to arsenic and lead and neuropsychological development in Mexican children. Environ Res 2001, 85(2):69-76

5. Wasserman GA, Liu X, Parvez F, Factor-Litvak P, Ahsan H, Levy D, et al: Arsenic and manganese exposure and children's intellectual function. Neurotoxicology 2011, 32(4):450-457.

6. Chen Y, Factor-Litvak P, Howe GR, Graziano JH, Brandt-Rauf P, Parvez F, et al Arsenic exposure from drinking water, dietary intakes of $B$ vitamins and folate, and risk of high blood pressure in Bangladesh: a populationbased, cross-sectional study. Am J Epidemiol 2007, 165(5):541-52.

7. Chen Y, Graziano JH, Parvez F, Liu M, Slavkovich V, Kalra T, et al: Arsenic exposure from drinking water and mortality from cardiovascular disease in Bangladesh: prospective cohort study. BMJ 2011, 342:d2431.

8. Haque R, Mazumder DN, Samanta S, Ghosh N, Kalman D, Smith MM, et al: Arsenic in drinking water and skin lesions: dose-response data from West Bengal, India. Epidemiology 2003, 14(2):174-82.

9. Ahsan $\mathrm{H}$, Chen Y, Parvez F, Zablotska L, Argos M, Hussain I, et al: Arsenic exposure from drinking water and risk of premalignant skin lesions in Bangladesh: baseline results from the Health Effects of Arsenic Longitudinal Study. Am J Epidemiol 2006, 163(12):1138-48. 
10. Wasserman GA, Liu X, Parvez F, Ahsan H, Factor-Litvak P, Kline J, et al: Water arsenic exposure and intellectual function in 6-year-old children in Araihazar, Bangladesh. Environ Health Perspect 2007, 115(2):285-9.

11. Wasserman GA, Liu X, Parvez F, Ahsan H, Factor-Litvak P, van Geen A, et al: Water arsenic exposure and children's intellectual function in Araihazar, Bangladesh. Environ Health Perspect 2004, 112(13):1329-33.

12. Argos M, Kalra T, Rathouz PJ, Chen Y, Pierce B, Parvez F, et al: Arsenic exposure from drinking water, and all-cause and chronic-disease mortalities in Bangladesh (HEALS): a prospective cohort study. Lancet 2010, 376(9737):252-8.

13. Ahmed MF, Ahuja S, Alauddin M, Hug SJ, Lloyd JR, Pfaff A, et al: Epidemiology. Ensuring safe drinking water in Bangladesh. Science 2006, 314(5806):1687-8.

14. Opar A, Pfaff A, Seddique AA, Ahmed KM, Graziano JH, van Geen A: Responses of 6500 households to arsenic mitigation in Araihazar Bangladesh. Health Place 2007, 13(1):164-72.

15. Hanchett S, Nahar Q, Van Agthoven A, Geers C, Rezvi MD: Increasing awareness of arsenic in Bangladesh: lessons from a public education programme. Health Policy Plan 2002, 17(4):393-401.

16. Paul BK: Arsenic contamination awareness among the rural residents in Bangladesh. Soc Sci Med 2004, 59 (8):1741-55.

17. Aziz SN, Boyle KJ, Rahman M: Knowledge of arsenic in drinking-water: risks and avoidance in Matlab, Bangladesh. J Health Popul Nutr 2006, 24(3):327-35.

18. Caldwell B: Tubewells and Arsenic in Bangladesh: Challenging a Public Health Sucess Story. International Journal of Population Geography 2003, 9:23-28.

19. Hadi A: Fighting arsenic at the grassroots: experience of BRAC's community awareness initiative in Bangladesh. Health Policy Plan 2003, 18(1):93-100.

20. Chen Y, van Geen A, Graziano JH, Pfaff A, Madajewicz M, Parvez F, et al: Reduction in urinary arsenic levels in response to arsenic mitigation efforts in Araihazar, Bangladesh. Environ Health Perspect 2007, 115(6):917-23.

21. Schoenfeld A: Area, Village, and Household Response to Arsenic Testing and Labeling of Tubewells in Araihazar, Bangladesh. New York City: Columbia University; 2005.

22. George CM ZY, Graziano JH, Mey JL, van Geen A: Environmental Health: Evaluation of the Effectiveness of Building Local Capacity to Conduct Arsenic Testing Services in Bangladesh; 2011

23. Ahsan H, Chen Y, Parvez F, Argos M, Hussain Al, Momotaj H, et al: Health Effects of Arsenic Longitudinal Study (HEALS): description of a multidisciplinary epidemiologic investigation. J Expo Sci Environ Epidemiol 2006, 16(2):191-205.

24. Caldwell BK, Smith WT, Lokuge K, Ranmuthugala G, Dear K, Milton AH, et al: Access to drinking-water and arsenicosis in Bangladesh. $J$ Health Popul Nutr 2006, 24(3):336-45.

25. Parvez F, Chen $Y$, Argos M, Hussain AZ, Momotaj H, Dhar R, et al: Prevalence of arsenic exposure from drinking water and awareness of its health risks in a Bangladeshi population: results from a large populationbased study. Environ Health Perspect 2006, 114(3):355-9.

26. Ahamed S, Kumar Sengupta M, Mukherjee A, Amir Hossain M, Das B, Nayak $B$, et al: Arsenic groundwater contamination and its health effects in the state of Uttar Pradesh (UP) in upper and middle Ganga plain, India: a severe danger. Sci Total Environ 2006, 370(2-3):310-22.

27. Farmer JG, Johnson LR: Assessment of occupational exposure to inorganic arsenic based on urinary concentrations and speciation of arsenic. Br J Ind Med 1990, 47(5):342-8.

28. Nixon DE, Mussmann GV, Eckdahl SJ, Moyer TP: Total arsenic in urine: palladium-persulfate vs nickel as a matrix modifier for graphite furnace atomic absorption spectrophotometry. Clin Chem 1991, 37(9):1575-9.

29. Van Geen A, Cheng Z, Seddique AA, Hoque MA, Gelman A, Graziano JH, et al: Reliability of a commercial kit to test groundwater for arsenic in Bangladesh. Environ Sci Technol 2005, 39(1):299-303.

30. Cheng Z, Zheng Y, Mortlock R, Van Geen A: Rapid multi-element analysis of groundwater by high-resolution inductively coupled plasma mass spectrometry. Anal Bioanal Chem 2004, 379(3):512-8.

31. Van Geen A, Ahsan H, Horneman AH, Dhar RK, Zheng Y, Hussain I, et al: Promotion of well-switching to mitigate the current arsenic crisis in Bangladesh. Bull World Health Organ 2002, 80(9):732-7.
32. Pan W: Akaike's information criterion in generalized estimating equations. Biometrics 2001, 57(1):120-5.

33. Yang CY, Chiu HF, Wu TN, Chuang HY, Ho SC: Reduction in kidney cancer mortality following installation of a tap water supply system in an arsenic-endemic area of Taiwan. Arch Environ Health 2004, 59(9):484-8.

34. Chiu HF, Yang CY: Decreasing trend in renal disease mortality after cessation from arsenic exposure in a previous arseniasis-endemic area in southwestern Taiwan. J Toxicol Environ Health A 2005, 68(5):319-27.

35. Chiu HF, Lin MC, Yang CY: Primary intracerebral hemorrhage mortality reduction after installation of a tap-water supply system in an arseniasisendemic area in southwestern Taiwan. J Toxicol Environ Health A 2007, 70(6):539-46.

36. Chang CC, Ho SC, Tsai SS, Yang CY: Ischemic heart disease mortality reduction in an arseniasis-endemic area in southwestern Taiwan after a switch in the tap-water supply system. J Toxicol Environ Health A 2004 67(17):1353-61.

37. Moore LE, Smith AH, Hopenhayn-Rich C, Biggs ML, Kalman DA, Smith MT: Decrease in bladder cell micronucleus prevalence after intervention to lower the concentration of arsenic in drinking water. Cancer Epidemiol Biomarkers Prev 1997, 6(12):1051-6.

38. Cascio C, Raab A: Jenkins RO, Feldmann J, Meharg AA. Haris PI. The impact of a rice based diet on urinary arsenic. J. Environ. Monit. 2011, 13(2):257-265.

39. Kile ML, Houseman EA, Breton CV, Smith T, Quamruzzaman Q, Rahman M, et al: Dietary arsenic exposure in Bangladesh. Environmental Health Perspectives 2007, 115(6):889.

40. DPHE: Situation Analysis of Arsenic Mitigation. Japan International Cooperation Agency June: Department of Public Health Engineering Bangladesh; 2010.

doi:10.1186/1476-069X-11-41

Cite this article as: George et al:: A cluster-based randomized controlled trial promoting community participation in arsenic mitigation efforts in Bangladesh. Environmental Health 2012 11:41.

\section{Submit your next manuscript to BioMed Central and take full advantage of:}

- Convenient online submission

- Thorough peer review

- No space constraints or color figure charges

- Immediate publication on acceptance

- Inclusion in PubMed, CAS, Scopus and Google Scholar

- Research which is freely available for redistribution 